\title{
Case Study in Design Engineering
}

\author{
W. Ernst Eder
}

\begin{abstract}
Designing is an essential activity to create products. The scope and activity of designing is different for various sorts of product, and some typical sorts of products are listed. Two extreme types of designing are compared. An example of conceptualizing in almost pure engineering design shows clearly that various abstract structures, models and methods can be used to enhance creativity, but the usual procedures of industrial design would not lead to such careful consideration of alternatives of construction.
\end{abstract}

\section{Introduction}

Designing is an essential activity for any controlled progress of society. Any process or tangible thing needed by at least some part of society must be thought out in advance, and then implemented and/or produced to make it a reality. This 'thinking out' often needs to create enough detail such that someone else can implement and/or produce, i.e. as a product of an industrial nature. Suitability for use, reliability, life cycle impacts [Eder 2001a and 2004a, Ernzer 2003, Graedel 1998, Guine 2002, Wimmer 2003], and other properties should also be estimated in advance. This is the essential scope of designing.

'Products' are 'results of a set of interrelated or interacting activities which transform inputs into outputs' [ISO9000:2000], and include 'services', 'software', 'hardware', and 'processed materials'. Conventionally these are also known as goods (hardware, processed materials and software) and services, or as artifacts and processes. Processes can change materials, energy, information, and often also humans and other animals - these are possible operands. Software in this sense is the record on a tangible medium of the capability of performing predefined processes, mainly on information. Some of these products have a substantial contribution from engineering, they are then called technical systems and technical processes [Hubka 1988 and 1996], and demonstrate a relationship as shown in figure 1 . Technical systems, humans (and other animals), information, management, and an active environment together are operators of the technical process that causes the transformation of the operand.

A rough definition of sorts of (especially tangible) products is needed in order to (a) compare types of

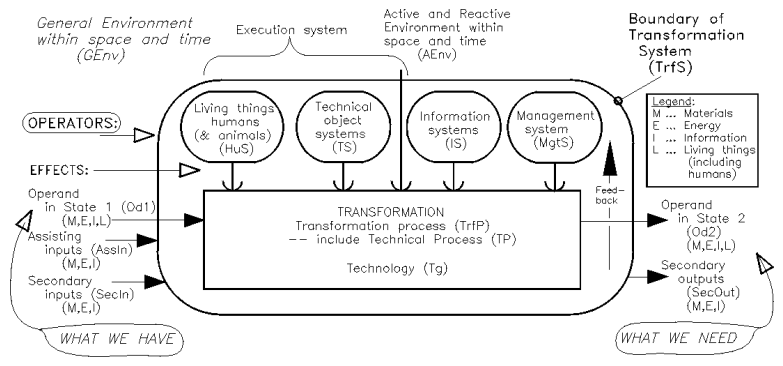

Figure 1. General Model of a Transformation System

design processes (processes that are intended to create the manufacturing and/or implementation instructions for a product) and to investigate their scope, (b) to provide a classification system for research publications [Eder 2003], and (c) to give some guidelines for design education in various disciplines [Eder 2001b, 2002b, 2004a, 2004c and 2005].

\section{Sorts Of Products}

A (non-linear, branched) 'scale' of artifacts (tangible products) can be proposed [Hubka 1996], for which the design processes will differ, and the deliverables from designing can be characterized.

Such a 'scale' can begin with purely artistic works, for which the designer is also the maker, and records of designing are often not available. Usability is usually not an issue, but appearance is.

Consumer products are consumable items and materials, usually for use by a member of the public.

Consumer durables are tangible products that have appropriate appearance and operability, project the 'right' image, and perform useful tasks at a suitable cost. Many of these are technical systems as well as attractive items. 
Bulk or continuous engineering products act as raw materials for other manufacture.

Industry products are bought by a manufacturing organization for assembling into their own products, as OEM goods (original equipment manufacture), COTS (commercial off-the-shelf products), etc.

Industrial equipment products are self-contained devices which perform more complex functions.

Special purpose equipment, including jigs, tooling, fixtures, and specialized manufacturing machines, robotics, handling and packaging machines, but also ocean-going ships and buildings for which appearance is very important.

Industrial plant usually consists of industrial equipment products, and devices to control and/or connect them.

Configuration products are items of equipment and/or industrial plant for which the parts are quantityproduced and standardized industrial equipment products (OEM, COTS) designed as modular interchangeable technical systems, which are assembled to the customers' requirements with little further modification.

Intangible products are typically information and services presented in the form of documents such as contracts, insurance policies, etc.

Software products are intangible products presented as computer programs of various kinds and for various purposes, including mechatronics and firmware, usually delivered on tangible media.

\section{Types Of Designing}

Designing in most cases involves a re-design of a previous product, and can range from innovative to routine. In some cases, a previous product does not exist, or must be altered so radically that a novel design process is more appropriate.

Types of designing can be characterized by extremes, which are caricatures of reality, see Table 1 . The procedures and responsibilities of designing are outlined under three scenarios. Designing is an essential part of integrated product development, but these concepts do not coincide. Figure 2 illustrates the typical overlaps of three concepts (for an indication of property classes, see [Eder 2006]).

In industrial design and integrated product development the aim is to create a visual model (on a computer screen, or as a solid reality) of a product. Designing is mainly performed in a studio, working on hardware. A direct mapping of 'Functional Requirements' to 'Design Parameters', as suggested by Suh [1989], is only possible for the esthetic (appearance) and ergonomic properties. All other external and internal properties can be achieved by
Table 1. Characteristics of Designing

\begin{tabular}{|c|c|c|}
\hline $\begin{array}{l}\text { Research } \\
\text { Objectives, } \\
\text { Design } \\
\text { Conditions } \\
\end{array}$ & $\begin{array}{l}\text { Design } \\
\text { Engineering }\end{array}$ & $\begin{array}{l}\text { Artistic } \\
\text { Architectural } \\
\text { Industrial Design }\end{array}$ \\
\hline $\begin{array}{l}\text { The object to be } \\
\text { designed, or the } \\
\text { existing } \\
\text { (designed) object }\end{array}$ & $\begin{array}{l}\text { Technical System; } \\
\text { primary: } \\
\text { functioning, } \\
\text { perform a task }\end{array}$ & $\begin{array}{l}\text { Product; primary: } \\
\text { appearance, } \\
\text { functionality }\end{array}$ \\
\hline $\begin{array}{l}\text { Representation } \\
\text { and analysis of } \\
\text { the object as } \\
\text { designed, and its } \\
\text { 'captured design } \\
\text { intent' }\end{array}$ & $\begin{array}{l}\text { Preparing for } \\
\text { manufacture, } \\
\text { assembly, } \\
\text { distribution, etc., } \\
\text { AI, CAD/CAM }\end{array}$ & $\begin{array}{l}\text { Rendering for } \\
\text { presentation and } \\
\text { display, product } \\
\text { range decisions }\end{array}$ \\
\hline $\begin{array}{l}\text { Design process } \\
\text { (for the object), } \\
\text { methodology, - } \\
\text { generating the } \\
\text { 'design intent' }\end{array}$ & $\begin{array}{l}\text { Theories of } \\
\text { designing, Design } \\
\text { Science, Formal } \\
\text { design } \\
\text { methodologies }\end{array}$ & $\begin{array}{l}\text { Intuitive, } \\
\text { collaborative, } \\
\text { interactive designing }\end{array}$ \\
\hline $\begin{array}{l}\text { Design } \\
\text { phenomenology }\end{array}$ & $\begin{array}{l}\text { Empirical, } \\
\text { experimental and } \\
\text { implementation } \\
\text { studies }\end{array}$ & Protocol studies \\
\hline Responsibilities & $\begin{array}{l}\text { Professional, } \\
\text { reliability, liability, } \\
\text { safety, public, } \\
\text { organization, } \\
\text { stakeholders }\end{array}$ & $\begin{array}{l}\text { Organization, } \\
\text { stakeholders }\end{array}$ \\
\hline Location & $\begin{array}{l}\text { Design/Drawing } \\
\text { Office }\end{array}$ & Studio \\
\hline
\end{tabular}

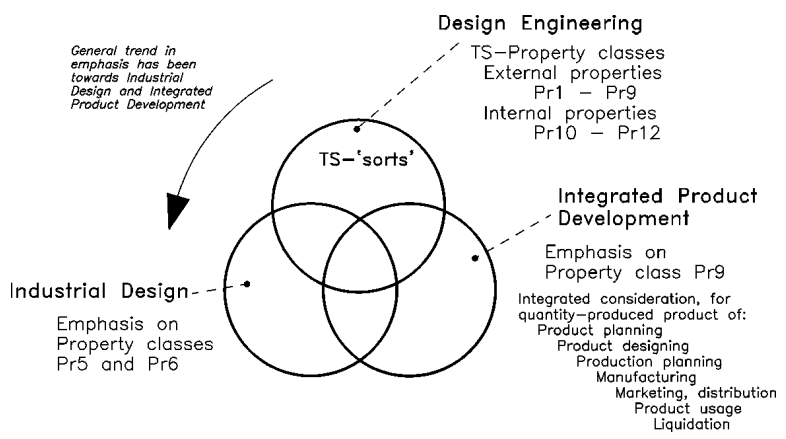

Figure 2. Scope of Sorts of Designing

several intermediate steps. The aim of industrial design is to generate a definitive proposal to be approved by management of an organization. Methods are mainly oriented towards creativity [Eder 1996]. Products with a substantial engineering content will need additional engineering design treatment to generate the needed manufacturing information.

The output of design engineering is a set of manufacturing drawings for constructional parts (or their computer-resident equivalents), assembly 
drawings, and parts lists - the internal properties. Documentation is needed to demonstrate that performance, strength and durability have been considered, usually by engineering science analysis. For novel design engineering, more abstract elements and structures are usable - transformation processes, technologies, functions, and organs [Hubka 1988, 1992 and 1996]. Creativity also has a role [Eder 1996], but systematic and methodical designing is preferable [Hubka 1992]. Industrial design and design engineering must frequently be coordinated. Nevertheless, most technical processes and systems impact on society in some way, and engineering designers must be aware of the possible consequences [Eder 2002a].

Architecture involves artistic designing of largescale buildings, and the responsibilities of the legal and contractual negotiations, and progress management of the project. All 'details' of civil engineering structural integrity and conformance to codes, services (water, heating/ventilating/airconditioning, electrical power, etc.) are delegated to engineering contractors, who assume the professional responsibility, and the legal liability.

\section{Design Engineering}

It seems that in recent years the subjects of design engineering and engineering design methodology have been neglected. A demonstration is needed.

As a verb, 'design' is understood as an activity and process, mainly performed by human beings. It intends to generate and establish a 'design intent', and includes operations such as the conventional four administrative phases of design engineering: (I) clarifying and defining a problem, searching for alternative solution possibilities (often at various levels of abstraction) and synthesizing - (II) conceptualizing, analyzing (often using the engineering sciences, and simulation using computer applications), evaluating, selecting among possible solutions, deciding, (III) embodying in a tangible form (e.g. layout designing, as sketches roughly to scale, and layout drawings correctly to scale with leading dimensions), (IV) detailing (e.g. detail and assembly designing, - 'the devil lies in the detail', a good concept can be ruined by poor detail design), communicating, verifying/checking/reflecting on the resulting product and its design process, representing a possible solution (several solutions at more abstract representation levels, a final choice for the definitive dimensional layout), preparing information, dividing or separating the problem into suitable parts and combining partial solutions, iterative proceeding, using methods and models, working in systematic and methodical ways alternating with opportunistic and intuitive ways, etc. [Eder 1995]. Designing may range from a routine level (where minor adjustments need to be made to a well-known product) to very innovative and novel (where prior experience hardly exists). The prior experience available to a design team will necessarily influence the quality of the proposed technical system.

With the transformation system shown in figure 1 , designers can develop a method for a novel system to be designed [Hubka 1988, 1992 and 1996]:

(P1) establish a design specification for the required system, by re-formulating the customers' needs into a full list of requirements as understood by the engineering designer, and by obtaining agreement with the customers (or their representative) and the management of the manufacturing organization;

(P2) establish the desirable and required output (operand in state $\mathrm{Od} 2$ ) of the transformation, the ultimate purpose of the product;

(P3) establish a suitable transformation process to change the operand from state Od1 to state $\mathrm{Od} 2$, its operations in detail, investigating possible alternative operations and their sequencing, and (if needed) establishing suitable inputs (operand in state Od1);

(P4) decide which of the operations in the transformation process will be performed by humans, and which of them by technical systems, alone or in mutual cooperation;

(P5) which technical systems (or parts of them) need to be designed at that point (i.e. do not yet exist);

(P6) establish a technology (with possible alternatives) for that transformation operation for which the technical system needs to be designed, and therefore the effects (as outputs) needed from the technical system to cause the transformation;

(P7) establish what the technical system needs to be able to do (its internal and cross-boundary functions, with possible alternatives) to produce these effects/outputs, and what its inputs need to be;

(P8) establish what organs (function-carriers in principle, with possible alternatives) can perform these functions, and what added functions (and organs) are recognized as needed (a function-means chain). A morphological matrix is useful for exploring candidate organs to solve each function, and to allow combining them into organ structures (as concepts). These organs can be found mainly in prior art, especially the machine elements, in a revised arrangement as proposed by Weber [Weber 1997, Eder 2004b, 2005]; 
(P9) establish with what constructional parts (in sketch-outline, in rough layout, in dimensionaldefinitive layout, then in detail and assembly drawings, with possible alternatives) are needed, and what additional functions (and organs, and constructional parts) are now revealed (evoked) as being needed (a more extended functionmeans chaining), to produce a full description of a future TS in the shortest time at lowest cost. Only those parts of this designing process that are thought to be useful are employed.

Redesign can be accomplished by:

(Pa) establishing a design specification for the revised system (step P1);

$(\mathrm{Pb})$ analyzing the existing system into its organs and (if needed) its functions (reversing steps (P8) and (P7) of the novel procedure);

(Pc) then following the last one or two parts of the procedure listed above for a novel system.

Consideration of life cycle issues is included in the outlined methodology, which necessarily also involves 'Design for X' knowledge and advice.

Neither novel design engineering nor re-designing can possibly be done in a linear procedure; feedback, iteration (repeating the operations with better understanding of the problem) and recursion (dividing a problem into smaller parts, solving, then recombining) are always needed. The possibilities of searching for alternatives is presented in several steps - is this not the essence of creativity? Possible analysis by engineering sciences exist at several stages. Each step should conclude with a cycle of review, including key-words such as 'substantiate', 'evaluate', 'select', 'decide', 'improve', 'optimize', 'verify', 'check' and 'reflect'.

\section{A Case Study}

The steps of design engineering used in this problem follow this procedural model [Hubka 1992 and 1996]. It includes the administrative phases (I), (II), and the first part of (III).

A small organization issued a contract to investigate fluid valves in general. The intention was to discover any possible gaps in the market offering of valves, with respect to functioning and size range. A design catalog should be one of the major results.

\section{(P1) Establish a List of Requirements - investigate alternatives}

Requirements are listed only under the most relevant TS-property (see [Eder 2006]) as judged by the engineering design team, i.e. not repeated in any other relevant property class. For this case, the design specification need not be detailed, some general statements will suffice, because the output should be a generic scheme of possible valve configurations (arrangements).

Pr1 Allow and guide fluid flow, allow continuous change from maximum to zero, change direction through $90^{\circ}$.

Pr1A React pressure of fluid inside flow channels, seal to outside

Pr1B Attach to standard pipes or tubing.

Pr1C Long life, reliable with easy repair and/or replacement

$\operatorname{Pr} 2$ Manufacturable by available means.

Pr3 No special requirements for transport packaging.

Pr4 Use only recyclable materials wherever possible.

Pr5 Easy to operate to change flow rate (coarse to fine adjustment as needed); low force or torque to achieve complete shut-off; remote operation may be desirable.

Pr6 Design for use of standard wrenches and tools, no special tooling.

Pr7 Corrosion resistant to fluid and to outside conditions; resistant to vibrations of pipes, water hammer, etc..

Pr8 Within the state of the art, and possible innovative extensions.

$\operatorname{Pr} 9$ Consider the supply chain for parts and completed valves.

Pr10-12 Usually no specifications needed.

A graphical statement of the problem is shown in figure 3 .

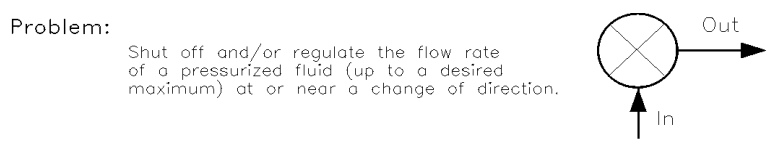

Figure 3. Valve - Problem Statement

\section{(P2, P3, P4) Establish a Transformation Process - investigate alternatives}

From a recognition of the problem, and its expanded statement in the design specification, the transformation process and its operations may be sketched as in figure 4 .

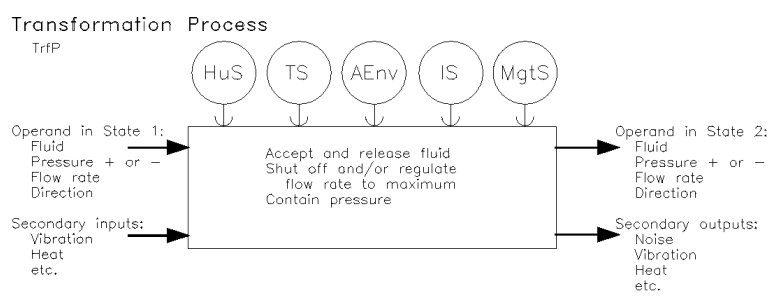

Figure 4. Valve - Transformation Process 


\section{(P5, P6) Establish Technologies - investigate} alternatives

Each of the operations needs a technology to perform the needed transformation. The technologies for this problem are shown in figure 5 .

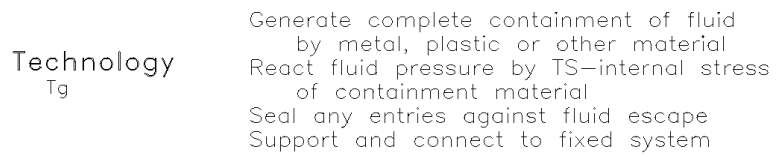

Figure 5. Valve - Technology

(P7) Establish TS-internal Functions - investigate alternatives

Using the operations in figure 4, and the technologies in figure 5, the TS-internal capabilities for action or reaction (the functions) can be diagrammed into a function structure, see figure 6

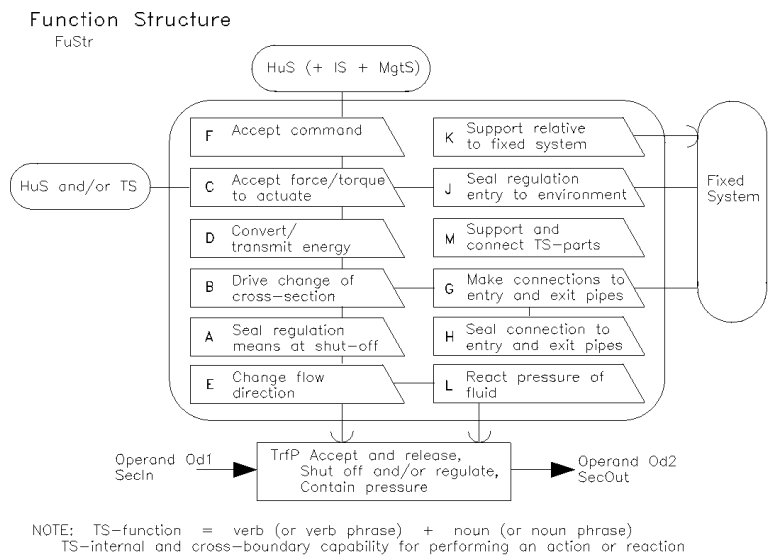

Figure 6. Valve - Function Structure

(P8) Establish Organs and Evoked Functions investigate alternatives

The individual functions can be solved separately, e.g. by using a morphological matrix. Functions may need to be combined or sub-divided, and possibly rephrased to investigate the possible alternative solutions. The morphological matrix for this case study is shown in figure 7.

Partial solutions, one from each function, can then be combined in various ways and changes in position (configuration, arrangement) of organs can be investigated. Three such combinations are illustrated in figure 8 as organ structures.

Placing sufficient material of suitable composition around these organ structures should now be relatively routine. Although in many cases 'the devil lies in the detail', i.e. a good solution-in-principle can be ruined by lack of attention to detail design, section (P9) of the procedure will not be covered in this case study.
1) Hond-lever opertated taper gate valve

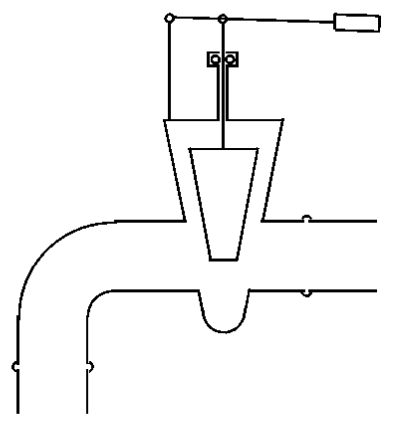

2) Hand-wheel operated membrane valve
$\mathrm{A} 7, \mathrm{~A} / \mathrm{a} 1, \mathrm{~B} 3, \mathrm{C} 1, \mathrm{E} 2, \mathrm{~F} 1, \mathrm{G} 7, \mathrm{H} 5, \mathrm{J1}, \mathrm{K} 1$

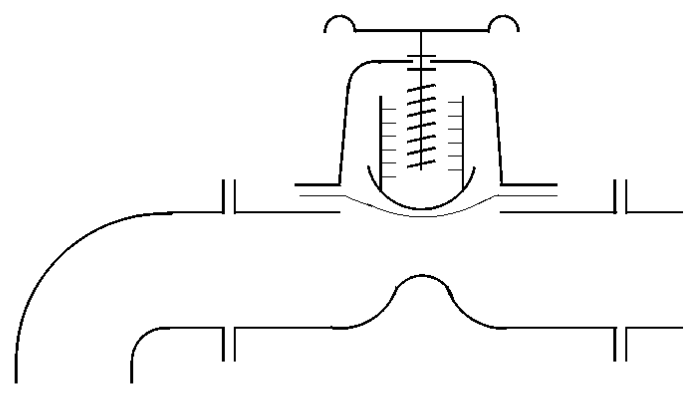

2) Hand-lever operated cone plug valve
$\mathrm{A}, \mathrm{A} / \mathrm{a} 2, \mathrm{~B} 7, \mathrm{C} 1, \mathrm{E} 1, \mathrm{~F} 1, \mathrm{G} 8, \mathrm{H} 1, \mathrm{~J} 4, \mathrm{~K} 1$

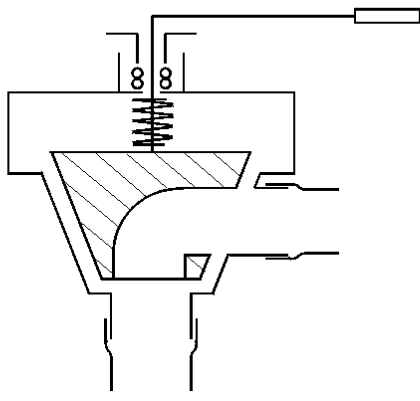

Figure 8. Valve - Organ Structures

\section{Closure}

For design engineering, the process of designing technical systems, a rational method based on Engineering Design Science can be proposed. Using the recommended graphical and verbal models, the solution space can be explored at an abstract level, and a large variety of solutions-in-principle (organ structures) can be found. These can then be evaluated according to the expanded design specification for a specific application, and the most appropriate arrangement selected for layout and detail design. The case study also demonstrates that a systematic approach can lead to creativity and innovation. 


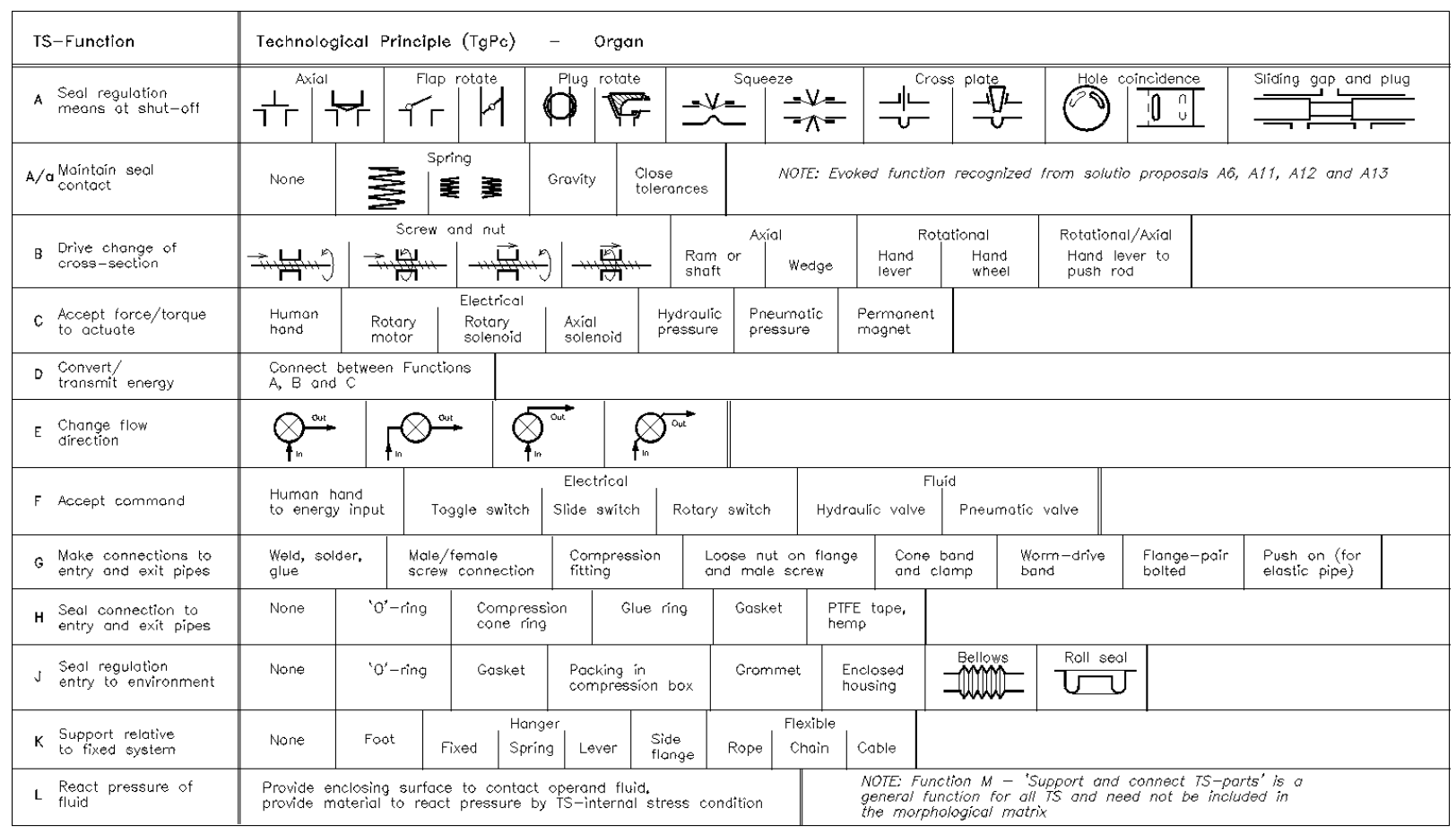

Figure 7. Valve - Morphological Matrix

\section{References}

Eder, W.E. (1995) "Engineering Design - Art, Science and Relationships", Design Studies, Vol. 16, pp 117-127.

Eder, W.E. (ed) (1996) WDK 24 - EDC - Engineering Design and Creativity - Proceedings of the Workshop EDC, Zürich: Heurista

Eder, W.E. (2001a) 'Designing and Life Cycle Engineering - A Systematic Approach to Designing', Proc. Inst. Mech. Eng. (UK), Part B, Jnl. of Engineering Manufacture, Vol 215, No B5, 2001, p. 657-672

Eder, W.E. \& Hubka, V. (2001b) 'Curriculum, Pedagogics, and Didactics for Design Education', in WDK 28, Proc. International Conference on Engineering Design, ICED01 Glasgow, 21-23 August 2001, Vol 4, p. $285-292$

Eder, W.E. (2002a) 'Social, Cultural and Economic Awareness for Engineers', in CSME Forum 2002, Queen's University, Kingston, ON, abstract p. 130, Proc on CD-ROM

Eder, W.E. (2002b) 'Education for Engineering and Designing, in Proc. International Design Conference _ Design 2002, Dubrovnik, May 14 17, 2002, Proc. on CD-ROM

Eder, W.E. (2003) 'A Typology of Designs and Designing', in DS 31 - Proc. ICED 03 Stockholm, p. 251-252 (Executive Summary), full paper number 1004 on CD-ROM, The Design Society

Eder, W.E. (2004a) 'Theory of Technical Systems - an Important Teaching Tool for Life Cycle Engineering', Proc. TMCE 2004, $5^{\text {th }}$ International
Symposium on Tools and Methods of Competitive Engineering, Lausanne, Switzerland, April 13-17, 2004 on CD-ROM

Eder, W.E. (2004b) 'Machine Elements - Integration Of Some Proposals', Proc. AEDS 2004 Workshop, The Design Society - Special Interest Group Applied Engineering Design Science, 11-12 Nov 2004, Pilsen, Czech Republic, on CD-ROM

Eder, W.E., Hubka V., and Benabdallah, H., (2004c) 'Educating for Engineering Design using Design Science', Proc. Inaugural CDEN Design Conference, McGill University, Montreal, July 2930, 2004, on CD-ROM; and on http:/www.cden.ca Journal of Engineering Design and Innovation (JEDI), Vol. 1E (Engineering Design Education), paper 01E2

Eder, W.E. (2005) 'Machine Elements - Revision and Outlook for Design Education', in press for Proc. Second CDEN International Conference, University of Calgary, 18-19 July 2005

Eder, W.E. (2005) 'Application of Design Methodology for Education', in Proc. Second CDEN International Conference, University of Calgary, Alberta, 18-19 July 2005 at Kananaskis Resort, paper 10007 on CDROM

Eder, W.E. (2006) 'Properties of Technical Systems - Key to Crossing Design Boundaries' in Proc. Third CDEN International Conference, University of Toronto, 24-26 July 2006, paper 10021 on CD-ROM

Ernzer, M. and Birkhofer, H. (2003) 'Life Cycle Design for Companies - Scaling Life Cycle Design Methods to the Individual Needs of a Company', in DS 31 - 
Proc. ICED 03 Stockholm, The Design Society, p. 393-394 and on CD-ROM

ISO9000:2000 Quality Management Systems Fundamentals and Vocabulary, Geneva: ISO, 2000

Graedel, T.E. (1998) Streamlined Life Cycle Assessment, Upper Saddle River, NJ: Prentice-Hall

Guine, J.G. (ed) (2002) Handbook on Life Cycle Assessment, Dordrecht: Kluwer Academic

Hubka, V., \& Eder, W.E. (1988) Theory of Technical Systems, New York: Springer_Verlag

Hubka, V., \& Eder, W.E. (1992) Engineering Design, Zürich: Heurista

Hubka, V., \& Eder, W.E. (1996) Design Science: Introduction to the Needs, Scope and Organization of Engineering Design Knowledge, London: Springer_Verlag, http://deseng.ryerson.ca/DesignScience/

Suh, N.P. Principles of Design, Oxford: University Press, 1989

Weber, C. and Vajna, S. (1997) 'A New Approach to Design Elements (Machine Elements)', in WDK 25 Proc. ICED 97 Tampere, Tampere University, Vol. 3, p. 685-690

Wimmer, W. and Züst, R. (2003) Ecodesign Pilot, Dordrecht: Kluwer

W. Ernst Eder, MSc, PEng

Professor Emeritus, Dr.h.c. (University of West Bohemia in Pilsen, Czech Republic)

Royal Military College of Canada, Department of Mechanical Engineering

Home Address: 107 Rideau Street, Kingston, Ontario, Canada K7K 7B2

Phone: $\mathrm{x}-1-613-547-5872$

Email: eder-e@rmc.ca 